Journal Economics and Management (JECMA)

Volume 1, No. 02, Februari 2021, p. 25-36

\title{
Analisis Metode Material Requirement Planning Pada Persediaan Bahan Baku Produk Vdrip Coffee di Rajaswa Coffee
}

\author{
Analysis of Material Requirement Planning Methods on Raw Material Inventory for \\ Vdrip Coffee Product at Rajaswa Coffee \\ Noer Dyah Rahmawati Zaeni ${ }^{1}$, Gian Fitralisma ${ }^{* 2}$, Syariefful Ikhwan ${ }^{3}$ \\ Program Studi Manajemen, Fakultas Ekonomi dan Bisnis, Universitas Muhadi Setiabudi, Brebes, \\ Indonesia \\ e-mail correspondance author: gianfitalisma@umus.ac.id
}

\begin{abstract}
ABSTRAK
Material Requirement Planning (MRP) merupakan metode yang dilakukan untuk melakukan perencanaan persediaan bahan baku. Tujuan dari penelitian ini adalah untuk melakukan analisis metode MRP yang cocok digunakan untuk perencanaan persediaan bahan baku produk Vdrip Coffee di Rajaswa Coffee. Teknik lotting yang digunakan dalam penelitian ini yaitu metode Lot For Lot (LFL) dan metode Period Order Quantity (POQ). Berdasarkan hasil penelitian yang telah dilakukan, maka metode yang paling efisien diterapkan di Rajaswa Coffee yaitu metode Period Order Quantity (POQ). Metode LFL menghasilkan biaya persediaan sebesar Rp 988.358, sedangkan metode POQ dapat menghasilkan biaya persediaan sebesar Rp 182.540. Artinya dengan metode POQ Rajaswa Coffee akan menghemat biaya sebesar Rp 805.818
\end{abstract}

Kata kunci: $M R P, L F L, P O Q$

\begin{abstract}
Material Requirement Planning (MRP) is a method used to plan raw material supplies. The purpose of this study was to analyze the MRP method which is suitable for planning the supply of raw materials for Vdrip Coffee products at Rajaswa Coffee. The lotting technique used in this research is the Lot For Lot (LFL) method and the Period Order Quantity (POQ) method. Based on the results of the research that has been done, the most efficient method applied in Rajaswa Coffee is the Period Order Quantity (POQ) method. The LFL method produces an inventory cost of Rp. 988,358, while the POQ method can produce an inventory cost of Rp. 182,540. This means that the POQ Rajaswa Coffee method will save you a cost of IDR 805,818
\end{abstract}

Keywords: $M R P, L F L, P O Q$

\section{INTRODUCTION}

Persediaan adalah barang yang sengaja disediakan atau disimpan oleh setiap perusahaan untuk jangka waktu tertentu. Persediaan ini pada umumnya bisa berupa bahan baku, produk setengah jadi, ataupun produk jadi yang akan dikeluarkan oleh perusahaan diwaktu yang tepat. Setiap perusahaan pasti akan menerima permintaan yang angkanya akan berbeda-beda. Perusahaan bisa menerima permintaan dengan angka yang tinggi dan perusahaan juga bisa menerima permintaan dengan angka yang rendah. Untuk mengantisipasi terjadinya kenaikan permintaan, maka perusahaan harus selalu memiliki persediaan.

Banyak sekali perusahaan yang mengalami masalah dalam sistem pengendalian persediaan bahan baku. Persediaan yang terlalu besar dapat meningkatkan jumlah biaya simpan, namun jika persediaan terlalu rendah maka akan menyebabkan terjadinya keadaan kekurangan bahan baku (stockout). Untuk itulah perusahaan harus menggunakan sebuah metode yang bisa menangani masalah perencanaan persediaan bahan baku.

Material Requirement Planning (MRP) adalah sebuah metode yang digunakan oleh perusahaan untuk menentukan jumlah kebutuhan bahan baku yang akan digunakan untuk produksi barang jadi[1]. Diharapkan dengan metode ini, jumlah pemesanan yang diterima oleh perusahaan akan mengoptimalkan jumlah kebutuhan bahan baku. Sehingga hal ini dapat menghemat biaya kebutuhan bahan baku yang akan dikeluarkan oleh perusahaan. Sedangkan

Submitted: Januari 2021, Accepted: Februari 2021, Published: Februari 2021

ISSN: 2746-0568 (online), Website: http://jurnal.umus.ac.id/index.php/jecma 
Journal Economics and Management (JECMA), Volume 1, No. 02, Februari 2021, p. 25-36

menurut [2] Material Requirement Planning (MRP) adalah sebuah metode penjadwalan dan perencanaan kebutuhan bahan baku yang akan digunakan dalam proses produksi. Metode ini dapat mengatasi masalah persediaan sehingga tingkat persediaan akan menjadi lebih rendah, jadwal produksi menjadi lebih tepat, dan hal ini dapat menghemat jumlah biaya yang dikeluarkan perusahaan [3]. Dari pengertian para ahli tersbut dapat ditarik kesimpulan bahwa MRP merupakan metode dalam merencanakan jumlah kebutuhan bahan baku dan sehingga tingkat persediaan akan menjadi lebih rendah dan biaya yang dikeluarkan juga menjadi rendah.

Saat ini, tren bisnis Coffee Shop sedang ramai dikalangan anak muda. Bahkan, pelaku bisnis Coffee Shop sendiri sebagian besar merupakan para pemuda pecinta coffee yang suka nongkrong. Seperti halnya kedai Rajaswa Coffee, usaha ini bergerak di bidang Coffee Shop dengan mengusung konsep Academic Coffee Shop. Selain menawarkan berbagai jenis coffee, kafe ini juga menawarkan berbagai jenis makanan ringan, menawarkan tempat yang asik dengan fasilitas wifi gratis, menawarkan fasilitas musik, menawarkan tempat untuk pengadaan event, serta menawarkan buku bacaan yang dapat dibaca secara gratis. Sejak awal berdiri di tahun 2019 sampai saat ini, kafe ini belum menggunakan metode MRP dalam perencanaan dan pengendalian kebutuhan bahan bakunya, hanya berdasarkan pengalaman saja. Sehingga, terkadang penjadwalan dan stok pembelian bahan baku selalu berubah-ubah tanpa melakukan analisis terlebih dahulu.

Berdasarkan latar belakang permasalahan di atas, maka penelitian ini akan fokus terhadap masalah penerepan metode MRP dengan menggunakan dua teknik lotting yaitu Lot for lot (Lfl) dan Period Order Quantity (POQ). Metode ini akan untuk menghitung perencanaan persediaan bahan baku untuk produk Vdrip Coffee pada Rajaswa Coffee, agar dapat meminimalkan biaya produksi. Sehingga sistem produksi Rajaswa Coffee akan berjalan lebih efektif dan efisien

\section{LITERATURE REVIEW Bahan Baku}

Menurut [4] bahan baku merupakan suatu barang mentah yang nantinya akan diolah melalui proses produksi menjadi barang jadi yang akan dipasarkan oleh perusahaan. Bahan baku juga dapat diartikan sebagai bahan yang membentuk sebuah barang jadi yang berasal dari barang impor, barang lokal, ataupun barang hasil olahan sendiri[5]. Sedangakan menurut [6] bahan baku yang digunakan dalam proses produksi pasti akan menempel dengan barang jadi menjadi satu kesatuan yang utuh. Jadi, bahan baku merupakan semua barang mentah yang akan diolah menjadi barang jadi, kemudian dipasarkan oleh perusahaan sehingga menghasilkan laba.

\section{Persediaan}

Menurut [7] persediaan merupakan barang milik perusahaan yang termasuk dalam aktiva, barang ini akan dijual dalam jangka waktu yang telah ditentukan. Persediaan juga dapat dikatakan sebagai kemampuan perusahaan untuk mengatur dan mengelola mengenai kebutuhan barang mentah, barang setengah jadi, dan barang jadi, agar barang-barang itu selalu tersedia dan dapat memenuhi kebutuhan setiap konsumennya[8]. Menurut [9] perusahaan sangat perlu untuk memiliki persediaan bahan baku agar proses produksi dari perusahaan dapat selalu berjalan lancar tanpa adanya hambatan mengenai bahan baku. Persediaan dapat diartikan juga sebagai kekayaan lancar yang dimiliki oleh perusahaan dalam bentuk barang mentah, barang setengah jadi, dan barang jadi[10]. Dengan demikian dapat diambil kesimpulan bahwa persediaan merupakan bagian dari kekayaan perusahaan yang berupa bahan mentah, bahan setengah jadi, dan bahan jadi.

Persediaan sendiri dapat dibagi menjadi 4 jenis, diantaranya: persediaan bahan mentah, persediaan barang setengah jadi, persediaan pasokan pemeliharaan/perbaikan/operasi, persediaan barang jadi. (1) persediaan bahan mentah sendiri merupakan semua bahan dasar yang sudah dibeli oleh perusahaan namun belum dilakukan proses produksi. Bahan tersebut biasanya dihasilkan dari supplier (pemasok bahan baku) ataupun dari sumber daya alam. (2) Persediaan barang setengah jadi merupakan bahan yang sedang berada dalam proses produksi namun belum selesai melewati proses produksi atau akan di proses lagi sehingga menjadi barang jadi. (3) Persediaan 
Journal Economics and Management (JECMA), Volume 1, No. 02, Februari 2021, p. 25-36

pasokan pemeliharaan/perbaikan/operasi merupakan persediaan yang sengaja disiapkan oleh perusahaan untuk mentenence mesin, reparasi, dan operasional untuk menjaga mesin agar tetap berfungsi dengan baik. (4) Persediaan barang jadi merupakan barang yang telah melewati seluruh proses produksi dan siap untuk dipasarkan ke konsumen.

\section{Pengendalian Persediaan}

Menurut [11] pengendalian persediaan merupakan sebuah kegiatan yang menetapkan besarnya persediaan dengan memperhatikan keseimbangan antara besar persediaan yang tersimpan dengan biaya yang akan di timbulkan. Sedangkan, menurut [12] pengendalian perusahaan merupakan rangkaian keputusan untuk menentukan tingkat persediaan perusahaan, kapan akan menambah persediaan dan berapa besar pesanan yang haris diterima, jumlah persediaan yang dibutuhkan pasti akan berbeda antara satu perusahaan dengan perusahaan lain tergantung volume produksi, jenis, dan prosesnya. Pengertian pengendalian perusahaan yakni kegiatan yang berasal dari rencana kegiatan yang saling berhubungan satu sama lain[6]. Pengendalian persediaan akan memastikan seluruh kegiatan produksi berjalan sesuai yang telah direncanaan. Dari beberapa pendapat para ahli, dapat ditarik benang merah bahwa pengendalian persediaan merupakan kegiatan penetapan persediaan dengan perencanaan-perencanaan sudah dilakukan sehingga kegiatan produksi akan berjalan dg baik.

\section{Material Requirement Planning}

MRP merupakan sebuah perencanaan yang dilakukan oleh manajemen produksi untuk melakukan suatu perencanaan kebutuhan bahan baku dalam proses produksi, sehingga bahan baku yang dibutuhkan perusahaan akan tersedia sesuai dengan jumlah yang telah direncanakan[13]. MRP dapat digunakan pada semua jenis industri terutama industri yang memiliki karakteristik job-shop. Job-shop merupakan jenis perusahaan yang memproduksi banyak produk dengan menggunakan mesin yang sama. MRP merupakan sebuah sistem pengendalian dan persediaan berdasarkan permintaan degan melakukan penjadwalan jumlah yang tepat dari semua bahan baku yang dibutuhkan untuk menghasilkan produk akhir yang diinginkan.

Dalam penerapannya ada beberapa hal dasar yang dibutuhkan untuk menyusun MRP, diantaranya[14]:

a. Master Production Schedule (MPS) merupakan jadwal utama yang digunakan sebuah perusahaan untuk memenuhi permintaan konsumennya.

b. Inventory Status Record merupakan sebuah informasi yang berisi tentang rekapan bahan baku yang sudah tersedia di dalam perusahaan.

c. Bill Of Material (BOM) merupakan data untuk menyusun produk sedail mungkin dengan komponen penyusun sehingga menjadi produk jadi yang utuh.

\section{Lot Sizing}

Proses lotting merupakan sebuah proses dalam menentukan besarnya jumlah pesanan optimal berdasarkan pada hasil perhitungan kebutuhan bersih[15]. Lot Sizing merupakan sebuah komponen MRP yang dikeluarkan pada perencanaan penerimaan order dan pengeluaran order[3]. Terdapat banyak teknik lot sizing, diantaranya:

a. Economic Quantity Order (EOQ)

Teknik ini digunakan untuk mendapatkan ukuran dengan meminimalkan biaya simpan dan biaya pemesanan. Rumus EOQ yaitu EOQ $=\sqrt{\frac{2 D S}{h}}$.

Keterangan:

$\mathrm{S}$ = Biaya untuk sekali pemesanan

$\mathrm{D}=$ Jumlah kebutuhan bahan baku per periode

$\mathrm{H}=$ Biaya penyimpanan persediaan 
Journal Economics and Management (JECMA), Volume 1, No. 02, Februari 2021, p. 25-36

b. Lot For Lot (LFL)

Di dalam metode ini, jumlah persediaan akan ditentukan sesuai jumlah permintaan saja. Artinya metode ini akan melakukan pemesanan bahan baku hanya ketika diperlukan perusahaan saja. Metode LFL juga memiliki rumus yang biasanya digunakan, yaitu:

$$
\mathrm{LFL}=\mathrm{TC}-\mathrm{BPs}+\mathrm{BPy}
$$

Keterangan:

TC : Total cost

BPs : : Biaya pemesanan

Bpy : Biaya penyimpanan

c. Period Order Quantity (POQ)

Metode POQ merupakan sebuah pengembangan dari metode EOQ yang digunakan untuk menghemat biaya persediaan dengan melakukan efektifitas frekuensi pemesanan supaya lebih terpola dengan rapi[16].

$\mathrm{POQ}=\sqrt{\frac{2 . S}{D . H}}$

Keterangan:

$S$ : biaya pemesanan

D : permintaan rata-rata per periode

$\mathrm{H}$ : Biaya penyimpanan per periode

\section{Penelitian Terdahulu}

Dalam penelitian [3] menggunakan metode MRP dengan 3 teknik lotting, diantaranya EOQ, FOQ, dan FPR. Hasil penelitian menunjukkan bahwa diantara 3 teknik lotiing yang digunakan, metode yang menghasilkan totalb biaya persediaan paling kecil yaitu metode FPR.

Peneliti [17], menggunakan LUC dan LFL, didapatkan bahwa pada metode LFL, perusahaan harus memiliki jaminan bahwa supplier bisa memenuhi kebutuhan perusahaan sesuai jadwal yang sudah dibuat. Sedangkan, dengan menggunakan metode LUC, ukuran pemesanan dihitung berdasarkan ongkor per unit paling kecil dari setiap pemesanan.

Peneliti [18] menggunakan metode Lot For Lot, Economic Order Quantity, dan Part Period Balancing. Dari ketiga metode tersebut, metode EOQ merupakan metode yang dapat meminimalkan biaya persediaan sebesar $68,39 \%$.

Peneliti [19] mendapatkan hasil penelitian bahwa dengan menggunakan metode POQ sangat cocok diterapkan dalam usaha tersebut. Karena dengan metode itu perusahaan dapat menghemat biaya persediaan sebesar Rp 3.783.124.

\section{METHODS}

Penelitian ini menggunakan jenis data kuantitatif, data kuantitatif merupakan data yang berbentuk angka-angka. Penelitian ini menggunakan sumber data primer, yaitu data yang dihasilkan langsung dari obyek penelitian. Data primer diperoleh melalui teknik wawancara dan melakukan observasi langsung terhadap Rajaswa Coffee di Desa Sitanggal Kabupaten Brebes.

Dalam penelitian ini, teknik analisis data yang digunakan yaitu analisis MRP dengan menerapkan 2 teknik lotting. Teknik lotting yang digunakan yaitu Lot for lot (LFL) dan Period Order Quantity (POQ). Di dalam penelitian ini, teknis analisis yang digunakan diantaranya:

1. Menghitung Master Production Schedule (MPS) dengan berpedoman pada permintaan terdahulu.

2. Melakukan perhitungan kebutuhan bahan baku dengan berdasarkan perhitungan MPS, Bill Of Material (BOM), Item Master, dan persediaan digudang ataupun yang sudah dalam proses pengiriman (sudah dipesan konsumen) 
Journal Economics and Management (JECMA), Volume 1, No. 02, Februari 2021, p. 25-36

3. Melakukan teknik lotting menggunakan metode LFL dan POQ.

Memilih salah satu dari metode LFL dan POQ yang menghasilkan biaya paling rendah

\section{Jadwal Induk Produksi Rajaswa Coffee}

Rajaswa Coffee telah melakukan peramalan permintaan yang menghasilkan Jadwal Induk Produksi (MPS) bulanan Rajaswa Coffee. kemudian, Rajaswa membuat jadwal produksi terperinci periode mingguan berdasarkan MPS yang telah dibuat. Jadwal produksi dibuat dengan melakukan asumsi bahwa dalam satu bulan ada 4 minggu. MPS bulanan Vdrip Coffee di Rajaswa Coffee disajikan dalam tabel 1 dan MPS mingguan Vdrip Coffee Rajaswa Coffee disajikan dalam tabel 2.

Tabel 1. MPS Bulanan Rajaswa Coffee

\begin{tabular}{lcc}
\hline \multicolumn{3}{c}{ Periode Bulanan (2020) } \\
\hline No & Bulan & Produksi (Cangkir) \\
\hline 1 & Agustus & 72 \\
\hline 2 & September & 80 \\
\hline 3 & Oktober & 92 \\
\hline \multicolumn{2}{l}{ Sumber: Rajaswa Coffee, 2020}
\end{tabular}

Tabel 2. MPS Mingguan Rajaswa Coffee

\begin{tabular}{cccccc}
\hline \multirow{2}{*}{ Bulan } & \multicolumn{4}{c}{$\begin{array}{c}\text { Periode Mingguan } \\
\text { (Cangkir) }\end{array}$} & $\begin{array}{c}\text { Jumlah } \\
\text { (Cangkir) }\end{array}$ \\
\cline { 2 - 5 } & $\mathbf{1}$ & $\mathbf{2}$ & $\mathbf{3}$ & $\mathbf{4}$ & \\
\hline Agustus & 18 & 18 & 18 & 18 & 72 \\
\hline September & 20 & 20 & 20 & 20 & 80 \\
\hline Oktober & 23 & 23 & 23 & 23 & 92 \\
\hline
\end{tabular}

Sumber: Rajaswa Coffee, 2020

\section{Struktur Produk dan Daftar Kebutuhan Bahan Baku}

Struktur produk atau bahan penyusun produk dari Vdrip Coffee di Rajaswa Coffee disajikan dalam gambar 1. Kemudian, Bill of Material (BOM) dalam satu cangkir disajikan dalam tabel 3.

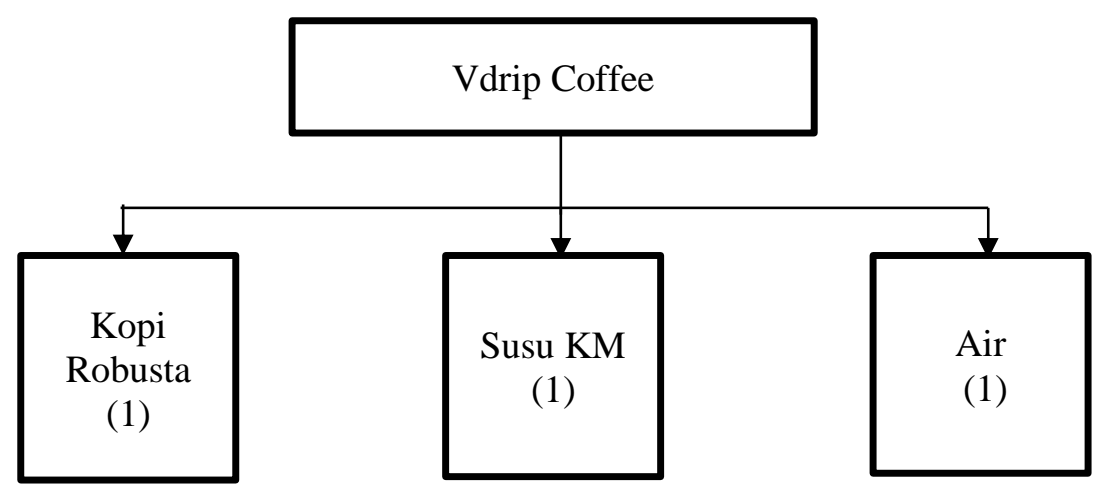

Gambar 1. Struktur Produk Vdrip Coffee

Sumber: Rajaswa Coffee, 2020 
Journal Economics and Management (JECMA), Volume 1, No. 02, Februari 2021, p. 25-36

Tabel 3. BOMs Vdrip Coffee

\begin{tabular}{ccccc}
\hline $\begin{array}{c}\text { Level } \\
\text { komponen }\end{array}$ & Item & Jumlah & Satuan & Sumber \\
\hline 0 & Vdrip Coffee & 1 & Cangkir & Buat \\
\hline 1 & Kopi Robusta & 13 & Gram & Lokal \\
\hline 1 & Air & 160 & Gram & Lokal \\
\hline 1 & $\begin{array}{c}\text { Susu Kental } \\
\text { Manis }\end{array}$ & 50 & Gram & Lokal \\
\hline \multicolumn{2}{c}{ Sumber: Rajaswa Coffee, 2020 }
\end{tabular}

\section{Data Persediaan dan Biaya}

Tabel 4 akan menyajikan data persediaan material yang untuk produk Vdrip Coffee di Rajaswa Coffee, sedangkan harga bahan baku disajikan dalam tabel 5. Biaya yang dikeluarkan oleh Rajaswa Coffee untuk melakukan pengadaan bahan baku disebut biaya pemesanan. Biaya pemesanan dalam Rajaswa Coffee sendiri meliputi biaya administrasi dan biaya pengiriman. Biaya pemesanan dan biaya penyimpanan disajukan dalam tabel 6 dan tabel 7.

Tabel 4. Data Persediaan Bahan Baku

\begin{tabular}{lccc}
\hline \multicolumn{1}{c}{ Item } & Persediaan Awal & Satuan & Sumber \\
\hline Kopi Robusta & 15 & $\mathrm{Kg}$ & Lokal \\
\hline Air & 171 & Liter & Lokal \\
\hline Susu Kental Manis & 15 & Kaleng & Lokal \\
\hline Sumber: Rajaswa Coffee, 2020 & & &
\end{tabular}

Tabel 5. Harga Bahan Baku

\begin{tabular}{lcccccc}
\hline \multicolumn{1}{c}{ Item } & $\begin{array}{c}\text { Persediaan } \\
\text { Awal }\end{array}$ & Satuan & & Harga & & \multirow{2}{*}{ Jumlah } \\
\hline Kopi Robusta & 15 & $\mathrm{Kg}$ & $\mathrm{Rp}$ & 32.000 & $\mathrm{Rp}$ & 480.000 \\
\hline Air & 9 & Galon & $\mathrm{Rp}$ & 4.000 & $\mathrm{Rp}$ & 36.000 \\
\hline Susu Kental Manis & 15 & Kaleng & $\mathrm{Rp}$ & 12.000 & $\mathrm{Rp}$ & 180.000 \\
\hline Sumber: Rajaswa Coffee, 2020 & & & & & &
\end{tabular}

Tabel 6. Biaya Pemesanan Bahan Baku

\begin{tabular}{|c|c|c|c|c|c|c|}
\hline \multirow{2}{*}{ No } & \multirow{2}{*}{ Jenis Biaya Pemesanan } & \multicolumn{5}{|c|}{ Biaya Pemesanan Bahan Baku (Rp) } \\
\hline & & \multicolumn{2}{|c|}{ Kopi Robusta } & \multicolumn{2}{|c|}{ Susu Kental Manis } & Air \\
\hline 1 & Administrasi & $\mathrm{Rp}$ & 2.000 & $\mathrm{Rp}$ & 1.000 & 500 \\
\hline 2 & Pengiriman & $\mathrm{Rp}$ & 96.000 & $\mathrm{Rp}$ & 10.000 & $\mathrm{Rp} 9.000$ \\
\hline & & $\mathrm{Rp}$ & 98.000 & $\mathrm{Rp}$ & 11.000 & Rp 9.500 \\
\hline
\end{tabular}

Sumber: Rajaswa Coffee, 2020

Tabel 7. Biaya Penyimpanan Bahan Baku

\begin{tabular}{cccccc}
\hline \multicolumn{4}{c}{ Biaya Penyimpanan Bahan Baku (Rp/unit) } \\
\hline Kopi Robusta & \multicolumn{2}{c}{ Susu KM } & \multicolumn{2}{c}{ Air } \\
\hline $\mathrm{Rp}$ & 100 & $\mathrm{Rp}$ & 50 & $\mathrm{Rp}$ & 30 \\
\hline Sumber: Rajaswa Coffee, 2020 & & &
\end{tabular}

\section{Perhitungan Jumlah Kebutuhan Bersih}

Sebelum menghitung jumlah kebutuhan bersih, maka perusahaan harus memiliki beberapa data terlebih dahulu, diantaranya:

1) Kebutuhan produksi setiap periode yang disajikan dalam MPS mingguan

2) Persediaan awal perusahaan

3) Rencana penetimaan dalam satu periode (receipt) 
Journal Economics and Management (JECMA), Volume 1, No. 02, Februari 2021, p. 25-36

Tabel 8. Kebutuhan Vdrip Coffee (Level 0)

\begin{tabular}{ccccccccccccc}
\hline Minggu & 1 & 2 & 3 & 4 & 5 & 6 & 7 & 8 & 9 & 10 & 11 & 12 \\
\hline $\begin{array}{c}\text { Vdrip Coffee } \\
\text { (Cangkir) }\end{array}$ & 18 & 18 & 18 & 18 & 20 & 20 & 20 & 20 & 23 & 23 & 23 & 23 \\
\hline Sumber: Rajaswa Coffee, 2020 & & & & & & & & & & & &
\end{tabular}

Rumus menghitung jumlah kebutuhan bahan baku level 1 per minggu yaitu menggunakan persamaan:

jumlah kebutuhan bahan baku $=\frac{\text { kebutuhan level } 0 \text { perming gu } x \text { kebutuhan dalam } 1 \text { cangkir kopi }}{\text { jumlah rencana penerimaan dalam sebulan }}$

Tabel 9. Kebutuhan Vdrip Coffee Level 1 (kg/minggu)

\begin{tabular}{lcccccccccccc}
\hline \multicolumn{1}{c}{ Minggu ke } & 1 & 2 & 3 & 4 & 5 & 6 & 7 & 8 & 9 & 10 & 11 & 12 \\
\hline Kopi Robusta & 2 & 2 & 2 & 2 & 3 & 3 & 3 & 3 & 3 & 3 & 3 & 3 \\
\hline Susu Kental Manis & 9 & 9 & 9 & 9 & 10 & 10 & 10 & 10 & 12 & 12 & 12 & 12 \\
\hline Air & 29 & 29 & 29 & 29 & 32 & 32 & 32 & 32 & 37 & 37 & 37 & 37 \\
\hline Sumber: Rajaswa Coffee, 2020 & & & & & & & & & & &
\end{tabular}

Tabel 10 sampai dengan 12 adalah table yang akan menyajikan data hasil perhitungan kebutuhan bersih setiap bahan baku.

Tabel 10. Kebutuhan Bersih Kopi Robusta (kg/minggu)

\begin{tabular}{lccccccccccccc}
\hline Minggu Ke & $\mathbf{0}$ & $\mathbf{1}$ & $\mathbf{2}$ & $\mathbf{3}$ & $\mathbf{4}$ & $\mathbf{5}$ & $\mathbf{6}$ & $\mathbf{7}$ & $\mathbf{8}$ & $\mathbf{9}$ & $\mathbf{1 0}$ & $\mathbf{1 1}$ & $\mathbf{1 2}$ \\
\hline Kebutuhan & & 2 & 2 & 2 & 2 & 3 & 3 & 3 & 3 & 3 & 3 & 3 & 3 \\
\hline Stock Awal & 15 & & & & & & & & & & & & \\
\hline Persediaan & 13 & 10 & 8 & 12 & 10 & 7 & 5 & 13 & 10 & 7 & 3 & 0 \\
\hline Receipt & & & & 10 & & & & 10 & & & & \\
Sumber: Rajaswa Coffee, 2020 & & & & & & & & & & &
\end{tabular}

Tabel 11. Kebutuhan Bersih Susu Kental Manis (kg/minggu)

\begin{tabular}{cccccccccccccc}
\hline Minggu Ke & $\mathbf{0}$ & $\mathbf{1}$ & $\mathbf{2}$ & $\mathbf{3}$ & $\mathbf{4}$ & $\mathbf{5}$ & $\mathbf{6}$ & $\mathbf{7}$ & $\mathbf{8}$ & $\mathbf{9}$ & $\mathbf{1 0}$ & $\mathbf{1 1}$ & $\mathbf{1 2}$ \\
\hline Kebutuhan & & 9 & 9 & 9 & 9 & 10 & 10 & 10 & 10 & 12 & 12 & 12 & 12 \\
\hline Stock Awal & 15 & & & & & & & & & & & & \\
\hline Persediaan & & 6 & 24 & 15 & 6 & 25 & 15 & 5 & 25 & 12 & 27 & 12 & 0 \\
\hline Receipt & & 15 & & & 15 & & & 15 & & 15 & & \\
\hline
\end{tabular}

Sumber: Rajaswa Coffee, 2020

Tabel 12. Kebutuhan Bersih Air (kg/minggu)

\begin{tabular}{cccccccccccccc}
\hline Minggu Ke & $\mathbf{0}$ & $\mathbf{1}$ & $\mathbf{2}$ & $\mathbf{3}$ & $\mathbf{4}$ & $\mathbf{5}$ & $\mathbf{6}$ & $\mathbf{7}$ & $\mathbf{8}$ & $\mathbf{9}$ & $\mathbf{1 0}$ & $\mathbf{1 1}$ & $\mathbf{1 2}$ \\
\hline Kebutuhan & & 29 & 29 & 29 & 29 & 32 & 32 & 32 & 32 & 37 & 37 & 37 & 37 \\
\hline Stock Awal & 171 & & & & & & & & & & & & \\
\hline Persediaan & 142 & 113 & 85 & 56 & 24 & 203 & 171 & 139 & 102 & 65 & 37 & 0 \\
\hline Receipt & & & & & 171 & & & & & & \\
\hline Sumber: Rajaswa Coffee, 2020 & & & & & & & & & &
\end{tabular}

\section{Analisis Metode Material Requirement Planning (MRP)}

Metode MRP yang digunakan dalam penelitian ini adalah metode LFL dan metode POQ. Metode LFL adalah metode yang akan memesan bahan baku hanya ketika diperlukan perusahaan saja. Perhitungan metode LFL dalam penelitian ini yaitu sebagai berikut: 
Journal Economics and Management (JECMA), Volume 1, No. 02, Februari 2021, p. 25-36

Rumus perhitungan biaya:

biaya pemesanan $=$ receipt $x$ biaya pemesanan

biaya penyimpanan $=$

jumlah persediaan di tangan (total jumlah penyimpanan $x$ biata pemesanan) $x$ biaya simpan/unit

total biasa persediaan = biaya pemesanan $x$ biaya penyimpanan

Tabel 13. Rencana Kebutuhan Kopi Robusta dan Biaya Persediaan dengan Metode LFL

\begin{tabular}{|c|c|c|c|c|c|c|c|c|c|c|c|c|c|}
\hline \multirow{3}{*}{$\begin{array}{c}\text { Kopi Robusta } \\
\text { Lead Time }=1 \mathrm{minggu} \\
\end{array}$} & \multicolumn{13}{|c|}{ Periode } \\
\hline & \multicolumn{5}{|c|}{$\begin{array}{c}\text { Agustus } \\
\text { (Minggu ke) } \\
\end{array}$} & \multicolumn{4}{|c|}{$\begin{array}{c}\text { September } \\
(\text { Minggu ke) }\end{array}$} & \multicolumn{4}{|c|}{$\begin{array}{c}\text { Oktober } \\
(\text { Minggu ke) }\end{array}$} \\
\hline & 0 & 1 & 2 & 3 & 4 & 5 & 6 & 7 & 8 & 9 & 10 & 11 & 12 \\
\hline Kebutuhan (Kg) & & 2 & 2 & 2 & 2 & 3 & 3 & 3 & 3 & 3 & 3 & 3 & 3 \\
\hline Persediaan Awal (Kg) & 15 & & & & & & & & & & & & \\
\hline Kebutuhan Bersih $(\mathrm{Kg})$ & & & & & & & 1 & 3 & 3 & 3 & 3 & 3 & 3 \\
\hline Receipt (Kg) & & & & & & 1 & 3 & 3 & 3 & 3 & 3 & 3 & 3 \\
\hline Penyimpanan $(\mathrm{Kg})$ & & 13 & 10 & 8 & 6 & 3 & 0 & 0 & 0 & 0 & 0 & 0 & 0 \\
\hline Jumlah Biaya Persedia & ni & bus & $a=$ & 78 & & & & & & & & & \\
\hline
\end{tabular}

Tabel 14. Rencana Kebutuhan Susu UHT dan Biaya Persediaan dengan Metode LFL

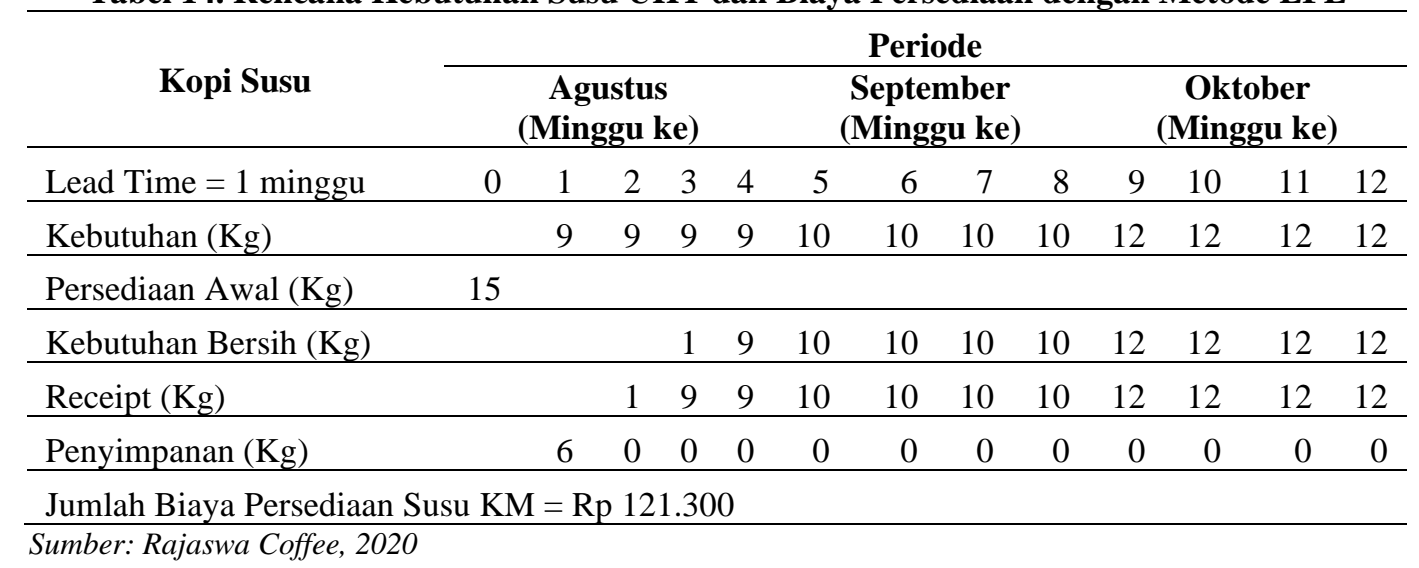

Tabel 15. Rencana Kebutuhan Air dan Biaya Persediaan dengan Metode LFL

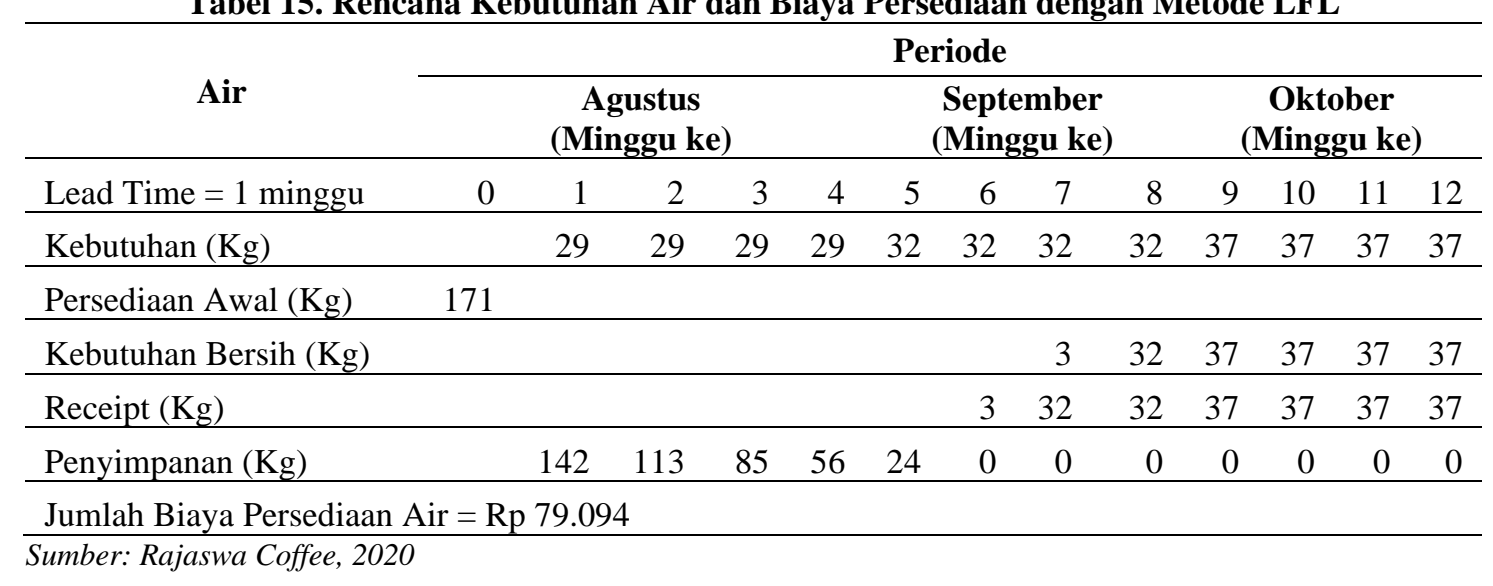


Journal Economics and Management (JECMA), Volume 1, No. 02, Februari 2021, p. 25-36

Tabel 16. Total Biaya Persediaan dengan Metode LFL

\begin{tabular}{clc}
\hline No & Bahan Baku & $\begin{array}{c}\text { Biaya Persediaan Dg } \\
\text { Metode LFL }\end{array}$ \\
\hline 1 & Kopi Robusta & Rp 787.964 \\
\hline 2 & Susu KM & Rp 121.300 \\
\hline 3 & Air & Rp 79.094 \\
\hline & Total Biaya & Rp $\mathbf{9 8 8 . 3 5 8}$ \\
\hline
\end{tabular}

Sumber: Rajaswa Coffee, 2020

Total biaya persediaan dengan metode LFL sebesar Rp 988.358. Selain menggunakan metode LFL, menghitung biaya persediaan juga dapat dilakukan dengan metode POQ. Rumus metode POQ yaitu adal dibawah ini:

Rumus POQ:

$P O Q=\sqrt{\frac{2 . S}{D . H}}$

$D=\frac{\text { jumlah periode } 5-12}{8}$

biaya penyimpanan $=1 \times$ biaya pemesanan

total biaya persediaan $=$ jumlah penyimpanan $x$ biaya simpan $/$ unit

Untuk hasil perhitungan persediaan dengan metode POQ akan ditampilkan dalam tabel 17.

Tabel 17. Rencana Kebutuhan Kopi Robusta dan Biaya Persediaan dengan Metode POQ

\begin{tabular}{|c|c|c|c|c|c|c|c|c|c|c|c|c|c|}
\hline \multirow{3}{*}{$\begin{array}{c}\text { Kopi Robusta } \\
\text { Lead Time }=1 \text { minggu } \\
\end{array}$} & \multicolumn{13}{|c|}{ Periode } \\
\hline & \multicolumn{5}{|c|}{$\begin{array}{c}\text { Agustus } \\
\text { (Minggu ke) }\end{array}$} & \multicolumn{4}{|c|}{$\begin{array}{l}\text { September } \\
\text { (Minggu ke) }\end{array}$} & \multicolumn{4}{|c|}{$\begin{array}{c}\text { Oktober } \\
(\text { Minggu ke) }\end{array}$} \\
\hline & 0 & 1 & 2 & 3 & 4 & 5 & 6 & 7 & 8 & 9 & 10 & 11 & 12 \\
\hline Kebutuhan (Kg) & & 2 & 2 & 2 & 2 & 3 & 3 & 3 & 3 & 3 & 3 & 3 & 3 \\
\hline Persediaan Awal (Kg) & 15 & & & & & & & & & & & & \\
\hline Receipt (Kg) & & & & & & & 20 & & & & & & \\
\hline Penyimpanan $(\mathrm{Kg})$ & & 13 & 10 & 8 & 6 & 3 & 16 & 13 & 10 & 7 & 4 & 1 & -2 \\
\hline \multicolumn{14}{|c|}{$\mathrm{POQ}=26$ periode } \\
\hline Jumlah Biaya Persediaa & $\mathrm{i} \mathrm{R}$ & ust: & $=\mathrm{R}$ & 10 & & & & & & & & & \\
\hline
\end{tabular}

Tabel 18. Rencana Kebutuhan Susu KM dan Biaya Persediaan dengan Metode POQ

\begin{tabular}{|c|c|c|c|c|c|c|c|c|c|c|c|c|c|}
\hline \multirow{3}{*}{$\begin{array}{c}\text { Susu KM } \\
\text { Lead Time }=1 \mathrm{minggu}\end{array}$} & \multicolumn{13}{|c|}{ Periode } \\
\hline & \multicolumn{5}{|c|}{$\begin{array}{c}\text { Agustus } \\
\text { (Minggu ke) }\end{array}$} & \multicolumn{4}{|c|}{$\begin{array}{c}\text { September } \\
(\text { Minggu ke) }\end{array}$} & \multicolumn{4}{|c|}{$\begin{array}{c}\text { Oktober } \\
(\text { Minggu ke) }\end{array}$} \\
\hline & 0 & 1 & 2 & 3 & 4 & 5 & 6 & 7 & 8 & 9 & 10 & 11 & 12 \\
\hline Kebutuhan $(\mathrm{Kg})$ & & 9 & 9 & 9 & 9 & 10 & 10 & 10 & 10 & 12 & 12 & 12 & 12 \\
\hline Persediaan Awal (Kg) & 15 & & & & & & & & & & & & \\
\hline Receipt (Kg) & & & 60 & & & & & & & & & & \\
\hline Penyimpanan $(\mathrm{Kg})$ & & 6 & 97 & 88 & 79 & 69 & 59 & 49 & 39 & 28 & 16 & 5 & -7 \\
\hline \multicolumn{14}{|c|}{ POQ $=6$ Periode } \\
\hline Jumlah Biaya Persediaa & u & & $\mathrm{Rp}$ & 37.35 & & & & & & & & & \\
\hline
\end{tabular}

Sumber: Rajaswa Coffee, 2020 
Journal Economics and Management (JECMA), Volume 1, No. 02, Februari 2021, p. 25-36

Tabel 19. Rencana Kebutuhan Air dan Biaya Persediaan dengan Metode POQ

\begin{tabular}{|c|c|c|c|c|c|c|c|c|c|c|c|c|c|}
\hline \multirow{3}{*}{$\begin{array}{c}\text { Air } \\
\text { Lead Time }=1 \text { minggu }\end{array}$} & \multicolumn{13}{|c|}{ Periode } \\
\hline & \multicolumn{5}{|c|}{$\begin{array}{c}\text { Agustus } \\
\text { (Minggu ke) }\end{array}$} & \multicolumn{4}{|c|}{$\begin{array}{c}\text { September } \\
\text { (Minggu ke) }\end{array}$} & \multicolumn{4}{|c|}{$\begin{array}{c}\text { Oktober } \\
(\text { Minggu ke) }\end{array}$} \\
\hline & 0 & 1 & 2 & 3 & 4 & 5 & 6 & 7 & 8 & 9 & 10 & 11 & 12 \\
\hline Kebutuhan $(\mathrm{Kg})$ & & 29 & 29 & 29 & 29 & 32 & 32 & 32 & 32 & 37 & 37 & 37 & 37 \\
\hline Persediaan Awal $(\mathrm{Kg})$ & 171 & & & & & & & & & & & & \\
\hline Receipt $(\mathrm{Kg})$ & & & & & & & 171 & & & & & & \\
\hline Penyimpanan $(\mathrm{Kg})$ & & 142 & 113 & 85 & 56 & 24 & 179 & 147 & 115 & 78 & 42 & 5 & -32 \\
\hline \multicolumn{14}{|c|}{$\mathrm{POQ}=4$ Periode } \\
\hline Imlah Biaya Persediaa & $=\mathrm{Rp} 3$ & 38126 & & & & & & & & & & & \\
\hline
\end{tabular}

Tabel 20. Total Biaya Persediaan Bahan Baku dengan Metode POQ

\begin{tabular}{clcc}
\hline No & Bahan Baku & $\begin{array}{c}\text { Biaya Persediaan Dg } \\
\text { Metode LFL }\end{array}$ \\
\hline 1 & Kopi Robusta & $\operatorname{Rp}$ & 107.034 \\
\hline 2 & Susu KM & $\operatorname{Rp}$ & 37.350 \\
\hline 3 & Air & $\operatorname{Rp}$ & 38.126 \\
\hline & Total Biaya & Rp & $\mathbf{1 8 2 . 5 1 0}$ \\
\hline Sumber: & Rajaswa Coffee, 2020 & &
\end{tabular}

Total biaya persediaan dengan menggunakan metode POQ sebesar Rp 182.510. Penyediaan baku dengan metode POQ sebaiknya untuk kopi robusta selama 26 periode, susu kental manis selama 6 periode dan Air selama 4 periode. Artinya metode yang paling efisien dalam pengendalian dan perencanaan bahan baku untuk produk Vdrip Coffee yang diterapkan di Rajaswa Coffee adalah metode POQ

\section{CONCLUSION}

Berdasarkan penelitian yang telah dilakukan, maka kesimpulan yang dihasilkan adalah metode Period Order Quantity (POQ) merupakan metode yang paling efisien untuk diterapkan di Rajaswa Coffee. Metode LFL menghasilkan biaya persediaan sebesar Rp 988.358, sedangkan metode POQ akan menghasilkan biaya persediaan sebesar Rp 314.370. Artinya dengan metode POQ Rajaswa Coffee akan hemat sebesar Rp182.540. Selain menggunakan metode LFL dan POQ, masih ada banyak lagi metode lain yang bisa diterapkan. Penelitian ini hanya menggunakan 2 teknik lotting, dalam penelitian selanjutnya, mungkin peneliti bisa menggunakan metode lain untuk dibandingkan dengan hasil metode POQ. Dalam menerapkan metode MRP, Rajaswa Coffee harus sering melakukan update data, agar tidak terjadi kesalahan dalam perencanaan persediaan bahan baku.

\section{REFERENCES}

[1] A. Greasley, Operations management. 2008.

[2] D. Kurnia, S. Bastuti, and B. N. Istiqomah, “Analisis Pengendalian Bahan Baku Pada Produk Tas Dengan Menggunakan Metode Material Requirements Planning ( MRP ) Untuk Meminimalkan Biaya Penyimpanan Di Home Industry Amel Collection," J. Ilm. Tek. dan Manaj. Ind., vol. 1, no. 1, pp. 22-28, 2018, doi: http://dx.doi.org/10.32493/jitmi.v1i1.y2018.p\%25p.

[3] N. Chamidah and T. A. Auliandri, "Analisis Persediaan Bahan Bau Produksi Beton 
dengan Metode Material Requirement Planning (MRP) pada PT. Merak Jaya Beton Plant Kedung Cowek Surabaya," INOBIS J. Inov. Bisnis dan Manaj. Indones., vol. 2, no. 4, pp. 505-512, 2019, doi: 10.31842/jurnal-inobis.v2i4.108.

[4] A. Irawan, "Analisa Persediaan Kapas Sintetik Dalam Proses Produksi Benang RHTO65Q12 47, 2 Dengan Menggunakan Metode Economic Order Quantity (Studi Kasus PT ...," JITMI (Jurnal Ilm. Tek. dan Manaj. ..., vol. 1, pp. 8-21, 2018, doi: http://dx.doi.org/10.32493/jitmi.v1i1.y2018.p\%25p.

[5] H. Herawati and D. Mulyani, "Pengaruh Kualitas Bahan Baku Dan Proses Produksi Terhadap Kualitas Produk Pada Ud. Tahu Rosydi Puspan Maron Probolinggo," Pros. Semin. Nas., vol. ISBN 978-6, pp. 463-482, 2016, [Online]. Available: http://jurnal.unej.ac.id/index.php/prosiding/article/view/3677.

[6] D. Wijaya, S. Mandey, and J. S. . Sumarauw, "Analisis Pengendalian Persediaan Bahan Baku Ikan Pada PT. Celebes Minapratama Bitung," J. Emba J. Ris. Ekon. Manaj. dan Bisnis, vol. 4, no. 3, 2016, doi: https://doi.org/10.35794/emba.v4i2.13114.

[7] D. Lestari, S. Subagyo, and A. D. Limantara, "Analisis Perhitungan Persediaan Bahan Baku Dengan Metode Fifo Dan Average (Study Kasus Pada Umkm Aam Putra Kota Kediri)," Cahaya Akt., vol. 09, no. 02, 2019, doi: https://doi.org/10.47047/ca.v9i2.56.

[8] D. H. D. Purnama and F. Pulansari, "Perencanaan Dan Pengendalian Bahan Baku Produksi Kerupuk Dengan Metode Mrp Untuk Meminimumkan Biaya Persediaan Bahan Baku Di Ud. Xyz," Juminten J. Manaj. Ind. dan Teknol., vol. 01, no. 04, pp. 49-57, 2020, doi: https://doi.org/10.33005/juminten.v1i4.86.

[9] D. rosa Indah and Z. Maulida, "Pengendalian Persediaan Bahan Baku Pada PT. Aceh Rubber Industries Kabupaten Aceh Tamiang," J. Manaj. dan Keuang., vol. 7, no. 2, p. 157, 2018, doi: 10.33059/jmk.v7i2.814.

[10] N. Apriyani and A. Muhsin, "Analisis Pengendalian Persediaan Bahan Baku Dengan Metode Economic Order Quantity Dan Kanban Pada Pt Adyawinsa Stamping Industries," Opsi - J. Optimasi Sist. Ind., vol. 10, no. 2, p. 128, 2017, doi: 10.31315/opsi.v10i2.2108.

[11] A. Asdi, S. Rizal, and D. Karyawati, "Analisis Pengendalian Persediaan Bahan Baku Dengan Menggunakan Bahan Baku Dengan Menggunakan Metode Economic Order Quantity (EOQ) Pada CV. Citra Sari Makasar," J. Profitab. Fak. Ekon. dan Bisnis, vol. 1, no. 1, 2017.

[12] E. Herjanto, "Pengantar Manajemen Operasi," Manaj. Operasi Ed. Ketiga, 2007.

[13] M. Arif, S. Supriyadi, and D. Cahyadi (Universitas Serang Raya), "Analisis Perencanaan Persediaan Batubara FX Dengan Metode Material Requirement Planning," J. Manaj. Ind. Dan Logistik, vol. 1, no. 2, p. 148, 2017, doi: 10.30988/jmil.v1i2.25.

[14] K. Z. Anggriana, "Analisis Perencanaan dan Pengendalian Persediaan Busbar Berdasarkan Sistem MRP (Material Requirement Planning) Di PT. TIS,” J. PASTI, vol. 9, no. 3, 2015.

[15] S. Saiddinur and M. Mustaqiem, "Sistem Persediaan Dan Pengendalian Stok Obat Menggunakan Metode Scm-Lot Sizing Pada Apotek," J. Penelit. Dosen Fikom, vol. 10, no. 1, pp. 41-50, 2019.

[16] M. F. Azwan and S. Norwati, "Analisis Pengendalian Persediaan Bahan Baku Dengan Menggunakan Metode Period Order Quantity (POQ) Pada Usaha Roti Kamper Bakery," J. Ris. Manaj. Indones., vol. 1, no. 1, pp. 1-5, 2019. 
[17] Z. S. Zahra and F. Fahma, "Implementasi Metode MRP untuk Pengendalian Bahan Baku Produk ABC Pada PT XYZ," Semin. dan Konf. Nas. IDEC 2020, no. November, pp. 1-11, 2020.

[18] K. I. R. Citro, Y. D. Suseno, and S. Sunarso, "Penerapan Material Requirement Planning Pada Persediaan Bahan Baku Dan Pengaruhnya Terhadap Efisiensi Biaya Persediaan (Survei Pada Roti Ganep Solo)," J. Ekon. dan Kewirausahaan, vol. 18, pp. 441-453, 2018.

[19] D. Raras Ati, Y. Djoko Suseno, and E. Widajanti, "Analisis Pengendalian Persediaan Bahan Baku dengan Menggunakan Metode Material Requirement Planning Pada CV. Aneka Karya Glass Kartasura," J. Ekon. dan Kewirausahaan, vol. 19, no. 1, pp. 1-8, 2019, doi: 10.1002/chem.202004280. 